\title{
A study on an Analysis of Success Factors of a Serious Game: In Case of "Anti-Aging Village"
}

\author{
Hyungsup Yoon \\ quesera21@smu.ac.kr
}

\begin{abstract}
This paper is a case study for serious game to derive key success factors by production process. So I selected an arcade serious game for the elderly named "Anti-aging Village" according to the strict criteria. This research method is so subjective and qualitative, so I complemented by using clinical trials and play test resuts and by intervlewing twice a director of this game. After analyzing a serious game Jfound sonie key success factors as follows; first, they had understood enough the state of gyowing elderly population in South Korea and designed gameplay well for improving cognitive function for the elderly. Second, they organized a development team including some experts and made use of the feature as a RF (Radio Frequency) card. Third, they validated the effectweness of a serious game through clinical trials and play test. This paper whl help for serious game design and could be the guideline for the development of seriousgame for eldely.
\end{abstract}

Keywords: Design, Serious Gane, Game Analysis, Game for Healthcare, Game for Cognitive Skills

\section{Introduction}

Serious games are compyter or video games designed for a primary purpose other than pure entertainment, but have other and more "serious" purpose [1, 2]. According to ADATE 2012 report, the-wofld market for serious games is up to $€ 2.35$ billion in 2011, and to show annual growth of $0 \%$ was expected [3]. According to a recent survey the serious games market in South Korea has grown steadily and reached up to 246 million US dollars. And people who engaged inserious game industry was grown up to 1,800 members [4]. However unlike the report the market for serious games in South Korea was not yet activated sufficiently. There are some problems in both sides demand and supply. In terms of demand there are some reasons, low awareness for serious games, distrust for potential effect for serious games and negative perception for video games. Also in terms of supply there are some reasons, low quality of serious games for consumers, effect of serious games is not sufficiently validated and not good user interface and so forth. The purpose of this paper analysis the game design elements by production process focusing on an arcade serious game "Anti-aging Village", this paper propose some suggestions for making effective serious games. So result of this case study will be helpful for serious game design and could be the guideline for the development of serious game for elderly.

\section{An Analysis of a Serious Game for the Elderly}

\subsection{Selection of a Serious Game for Case Study}

I selected a game for case study as follows; recently developed serious game with awardwining, with a number of media exposure, with innovation so aimed new market and easy accessibility of data and so forth. "Anti-aging Village" is an excellent serious game in South 
Korea, takes more than a billion of research and development costs. A game developer Uniana Co. Ltd. which is specialized in arcade game development since 1988 and Asan Medical Center did collaborative research and development. The clinical research trials was passed by IRB (Institutional Review Board) and got the official approval. Also the games were installed in 25 Centers for Welfare over the country and receive user feedback on the effect of the serious game "Anti-aging Village" from over 100 seniors.

\subsection{The Methodology of Case Study}

I make use of methodology of case study step-by-step analysis of the game design in this study. This research method is so subjective and qualitative, and has limitations. So I complemented by using clinical trials and its results, the validation study for effectiveness of serious game for more objective and quantitative research.[5] Also I interviewed twice a director who was directly involved in the research and development and experiment. So I was able to analyze the serious game from different angles.

\section{An Analysis on the Key Success Factor of Seribus Game "Anti-aging Village" by Production Process}

Serious games need a lot of collaboration yith experts and have to be validated for its effectiveness. I'll analyze the key success factors of serious game "Anti-aging game" by production process in this paper. So I divided the development process into three steps "preproduction, production and post-production" and analyzed them by each step.

\subsection{Introduction of "Anti-aging Village"}

A serious game "Anti-aging Village" won the prize in the Korea Game Awards 2013, in the sector of serious, games. Development team has been collaborated with some professors of department of game engineering in Hoseo University for improved cognitive function, got the advisory statements from a Director of Rehabilitation Medicine of Asan Medical Center, and got the help from a professor of nursing of Sungshin Womens University.

\begin{tabular}{|c|l|}
\hline Title & Anti-aging Village \\
\hline
\end{tabular}




\subsection{Gameplay Flow}

Introduction of "Anti-aging Village"

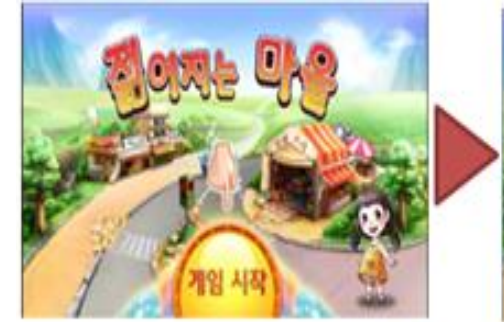

Game Start (Press Start Button)

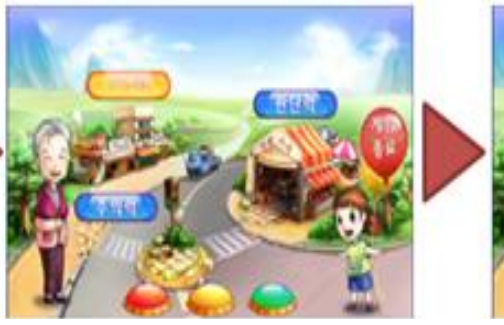

Select Cognitive Function

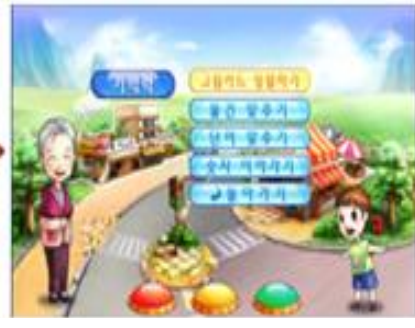

Select games at levels

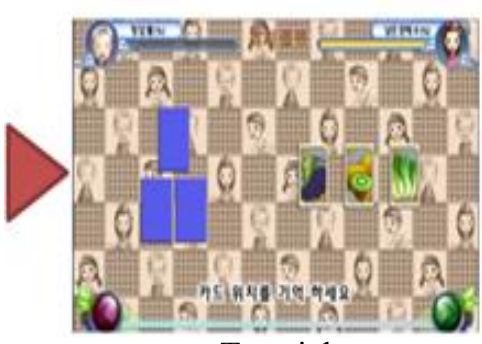

Tutorial

\subsection{Features of the Game "Anti-aging Village"}

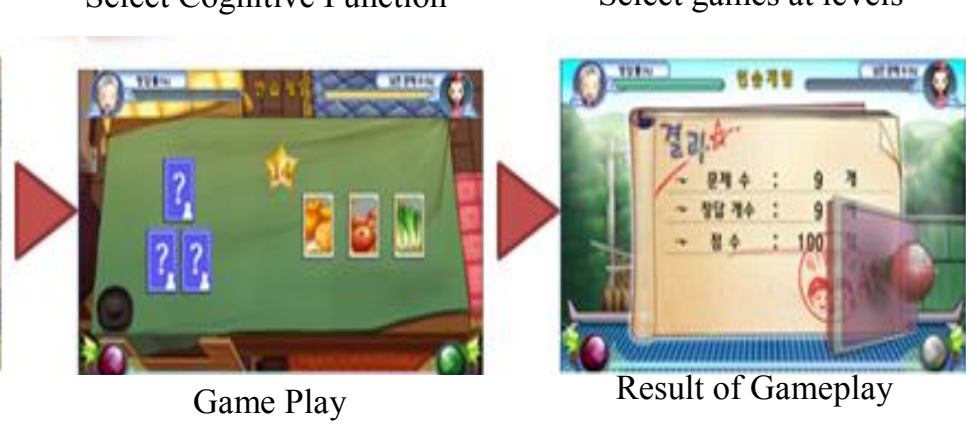

\begin{tabular}{|c|l|}
\hline Platform & $\begin{array}{l}\text { Select as arcade game for the accessibility for the elderly, not PC or Smart } \\
\text { phone game }\end{array}$ \\
\hline Characters & $\begin{array}{l}\text { Set the character not too old(Most of the elderly do not tend to admit } \\
\text { themselyes are ofd) }\end{array}$ \\
\hline Back ground Story & $\begin{array}{l}\text { Players can go back } 30 \text { years ago, and go around the town with their } \\
\text { grand ons in a variety of situations. }\end{array}$ \\
\hline Sound and Effects & Use the classic and traditional music for helping concentration \\
\hline User Interface & Set UI as simple as possible considering their cognitive abilities \\
\hline Hardware & Make corner rounded for safety \\
\hline
\end{tabular}

In this game the most unique thing is the RF (Radio Frequency) card system. Registered game players can review the result of game play individually in the website and they can improye cognitive functions through systematic training by this serious game.

\subsection{Key Success Factors in Stage of Pre-production}

\subsubsection{In the Step of Research for Demand}

- They (Development Team) focused the rapid increase of the elderly in South Korea. And the number of dementia is increasing rapidly. The elderly population is increasing by $12.2 \%$ in 2012, and expected to reach $20.8 \%$ in 2026 [6]. The increase of elderly population and prevalence of dementia in South Korea are as follow; 


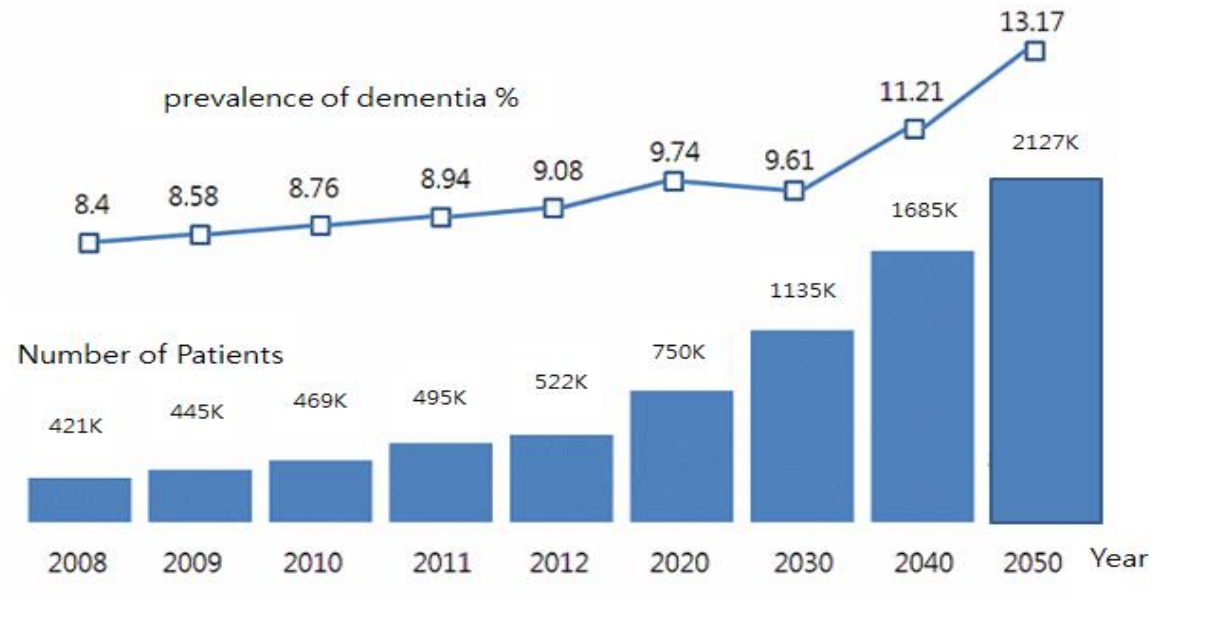

Figure 1. Prospects of Elderly Population and Prevalence of Dementia in South Korea [7]

- They thought that elderly need serious games to improve cognitive function in dementia

- They decided the arcade game platform and gameplay for improving cognitive function for the elderly. In general, elderly people prefer smple user interface and simple game play. They think that arcade game platform with simple control is more preferable for the elderly.

- They convinced that serious game is effective for healthcare after benchmarking the serious game "Re-Mission" developed by HopeLab. "Re-Mission is a successful serious game which was made for the treatment of pediatric blood cancer patients. Co-authors including Pamela Kato verified that "Re-Mission" improves behavioral outcome in people with cancer [8].

- They forecast that B2B (business to business) model is preferable considering the situation in which the patient's family should bear the cost of treatment of dementia because of lack of a national management system in South Korea.

\subsubsection{In the Step of:Planning}

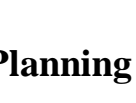

- They decided develop a serious game for improving cognitive functions while having fun.

- They designed a gameplay for improving 3 major cognitive functions: attention, memory and judgment with the medical experts. (See Figure 2)

They determined a guideline for developing a serious game for the elderly as follows ;

\begin{tabular}{|l|l|}
\hline \multicolumn{1}{|c|}{ Key points } & \multicolumn{1}{c|}{ Considerations } \\
\hline Universality & $\begin{array}{l}\text { Using general materials for game design to effective } \\
\text { communication between aged people and their family }\end{array}$ \\
\hline personalization & Provide options for personal preference \\
\hline Effective feedback & Provide clear audio-visual feedback at each stage \\
\hline UX design & $\begin{array}{l}\text { - Intuitive visual design } \\
\text { - UI design for consistency } \\
\bullet\end{array}$ \\
\hline
\end{tabular}




\begin{tabular}{|l|l|}
\hline $\begin{array}{l}\text { Minimize the } \\
\text { physical efforts }\end{array}$ & Minimize the physical efforts in playing games \\
\hline Accessibility & Easy access and easy play \\
\hline
\end{tabular}

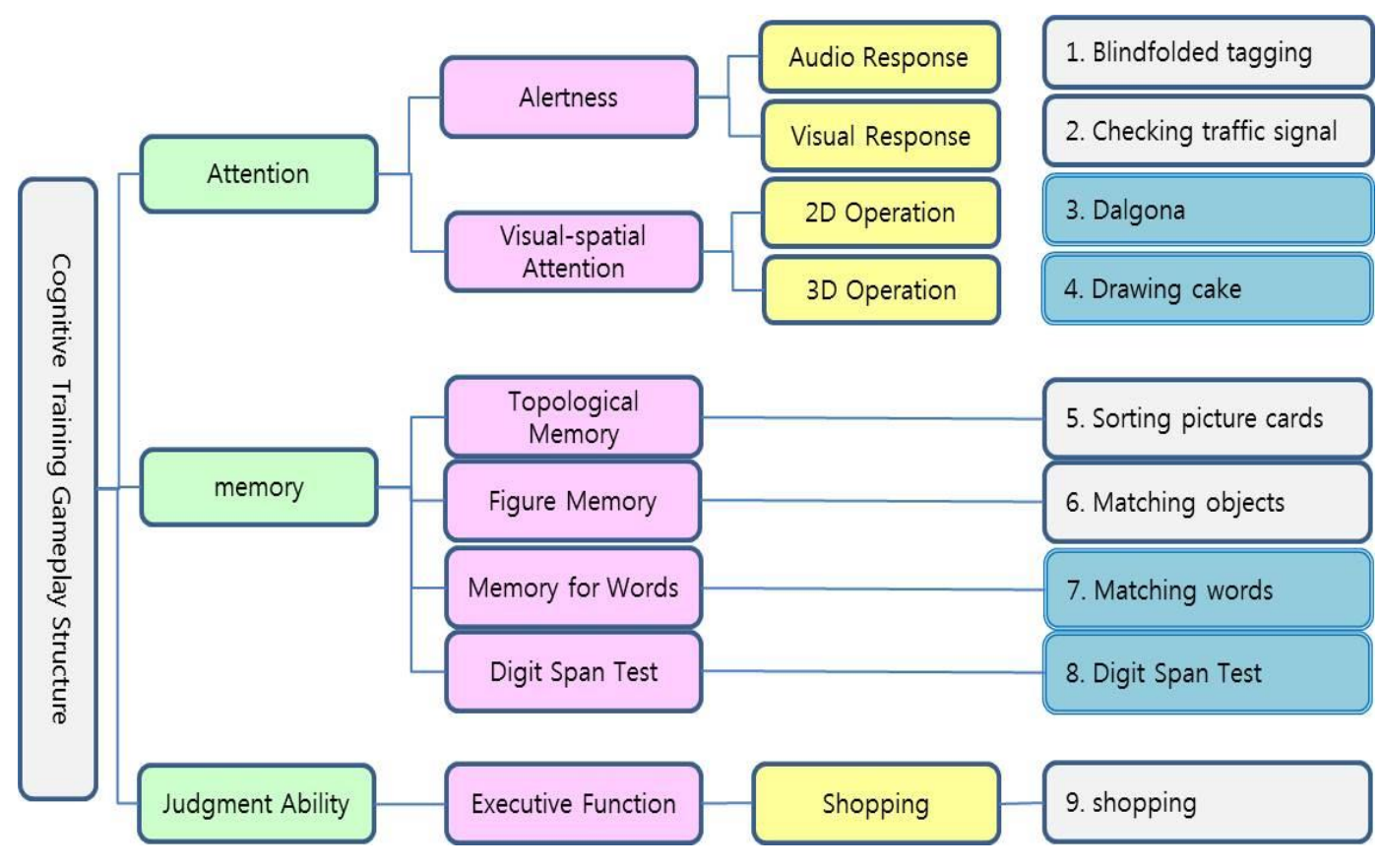

Figure 2. Cognitive Training Gameplay Structure

3.4.3. Funding: They funded from government agencies and their own capital without fund from venture capital or loan from bank. They thought that investment or funding from outside was more desirable rather than loan from bank. Because of developing a serious game for research and development costs are not only high but also risk is high. Fortunately they prepared total budget 1 million US dollars for developing a serious game. Total budget was composed of some subsidjes, 0.6 million US dollars from KOCCA (Korea Creative Content Agency), 0.2 million Us dollars from SBA(Seoul Business Agency) and the rest of that was funded from its own eapital. This budget scale of developing a serious game is one of the biggest projects in South Korea.

\subsection{Key Success Factors in Stage of Production}

They constructed effective development team including medical experts and experts group for the elderly. (See Figure 3)

- They prepared RF (Radio frequency) card and server system. So the game machine could identify the game player, save the record of personal gameplay and check all the players statistics.(See Figure 4)

- All the statistics of the gameplay could help update game and propose useful information for welfare policy development for the elderly.

- Also all players who play this serious game could review their scores and progress for each game and improve cognitive function through the repeated training.

- Each game play data stored central game server by individual RF card, so we can review the game play data as follows; name, age, weight, sex, result of game 
play(play times, clear times, levels, success and failure rate at each game, response time, etc.,)

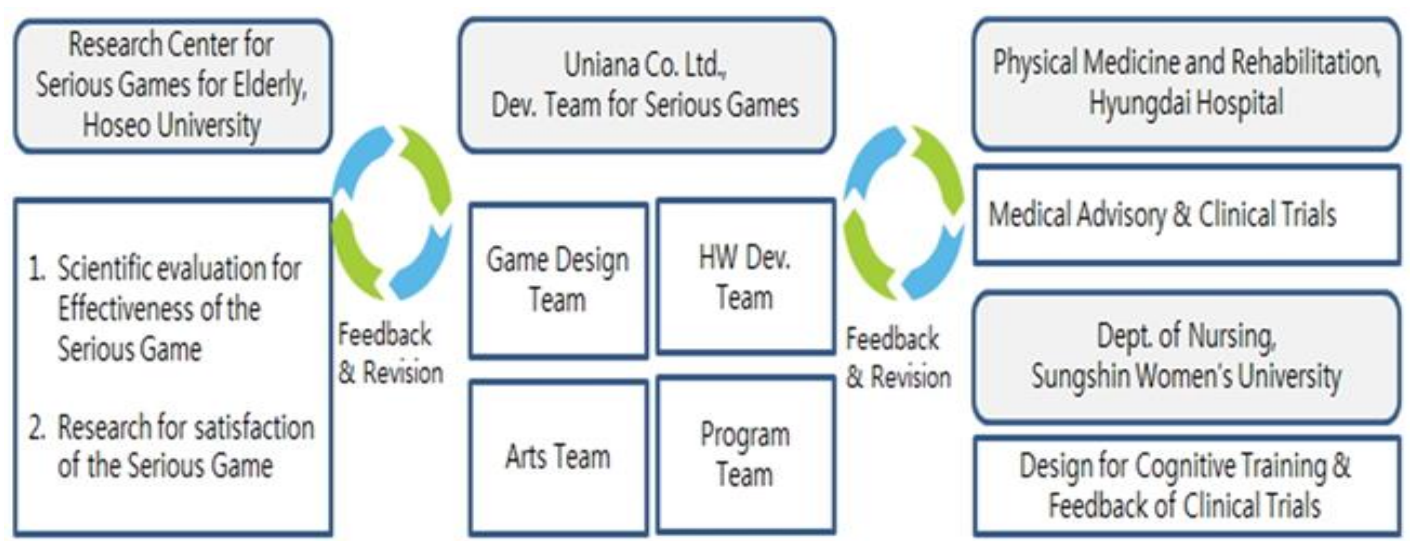

Figure 3. Organization and Roles in the Development and Advisory

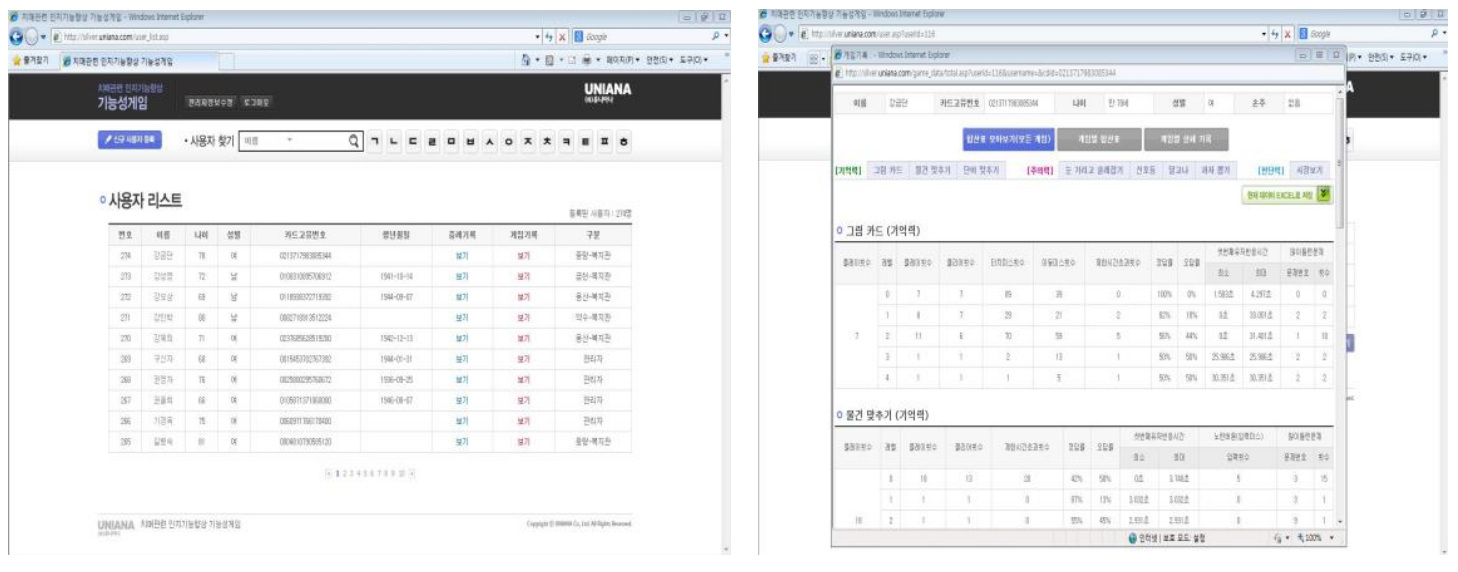

Figure 4. A Screenshot of Central Game Server System

(O)

\subsection{Key success factors in stage of post-production}

\subsubsection{Clinicar Research Trials and Approval}

- The clinical research trials was passed by IRB (Institutional Review Board) and got the official approval.

- Clinical trials should be assessed by blinded raters to limit the risk of introducing bias [9].

- Also the games were installed in 25 welfare centers over the country and receive user feedback on the effect of the serious game "Anti-aging Village" from 100 seniors.

- They could confirm that cognitive function is improved through play test [10].

- Overview of clinical research

\begin{tabular}{|l|l|}
\hline Research Director & $\begin{array}{l}\text { Director of Physical Medicine and Rehabilitation in Asan } \\
\text { Medical Center }\end{array}$ \\
\hline Researchers & 2 doctors and 1 professor of Dept. of Nursing \\
\hline
\end{tabular}




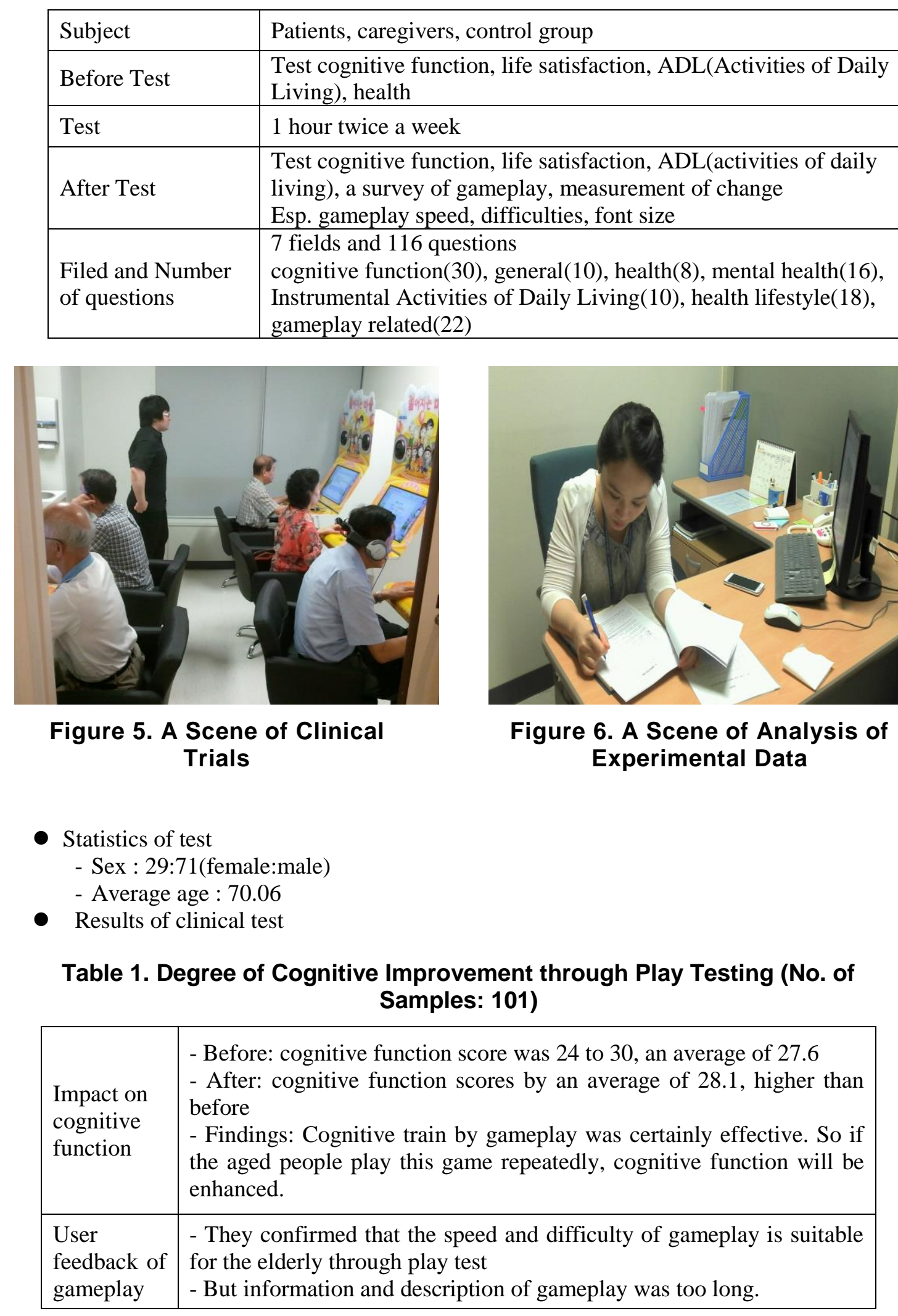




\begin{tabular}{|r|c|c|c|c|c|}
\hline \multirow{2}{*}{} & \multirow{2}{*}{ Sex } & \multicolumn{2}{|c|}{ Before - After } & \multirow{2}{*}{$t$} & $p$ \\
\cline { 3 - 4 } & average & $\begin{array}{c}\text { Standard } \\
\text { Deviation }\end{array}$ & & \\
\hline $\begin{array}{r}\text { Score of } \\
\text { Cognitive }\end{array}$ & male & -0.48 & 1.62 & -1.61 & .119 \\
\cline { 2 - 6 } Functions & Female & -0.51 & 1.47 & -2.90 & .005 \\
\cline { 2 - 6 } & Total & -0.5 & 1.51 & -3.32 & .001 \\
\hline
\end{tabular}

\subsubsection{Installation and Distribution}

After clinical trials and play test they completed arcade game consoles, distributed 25 game consoles at 25 centers for dementia support.

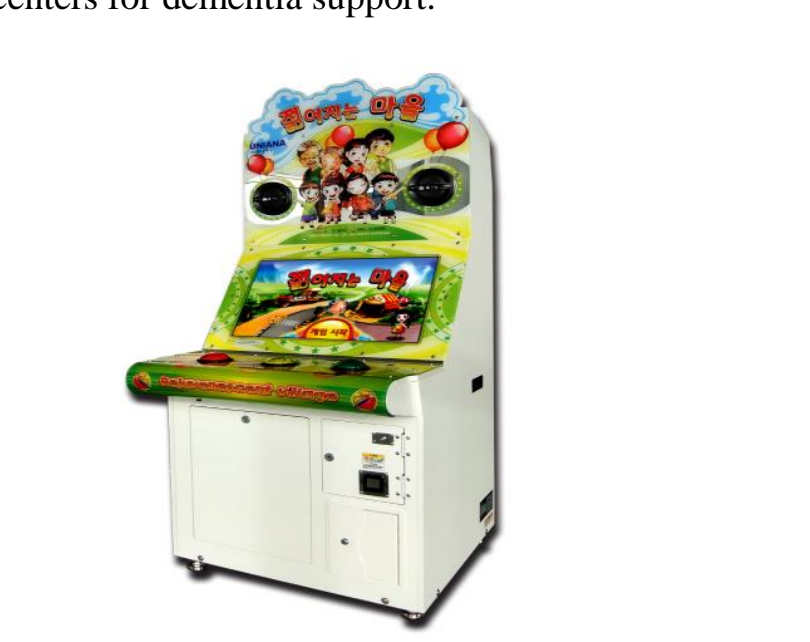

Figure 7. Arcade Game Console "Anti-aging Village"

\subsubsection{Play Test Over and Over}

- They had play test nany times at every center for dementia support.

- They found good points or not though many play tests.

- They tested gameplay about game speed, difficulty of gameplay and enough information.

- After play test they were able to get following points.

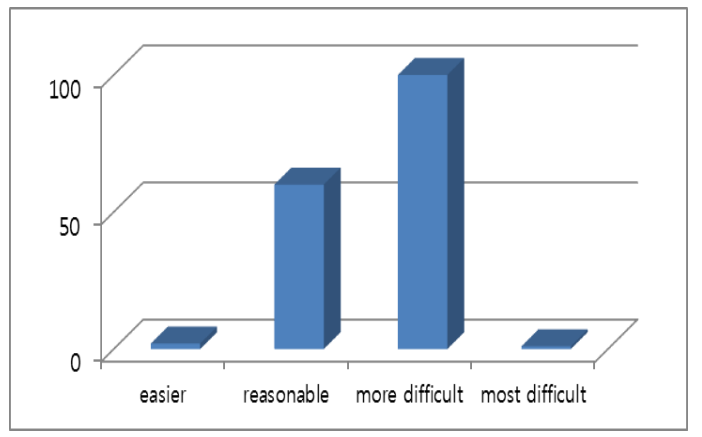

Figure 8. Survey Results for Gameplay Speed

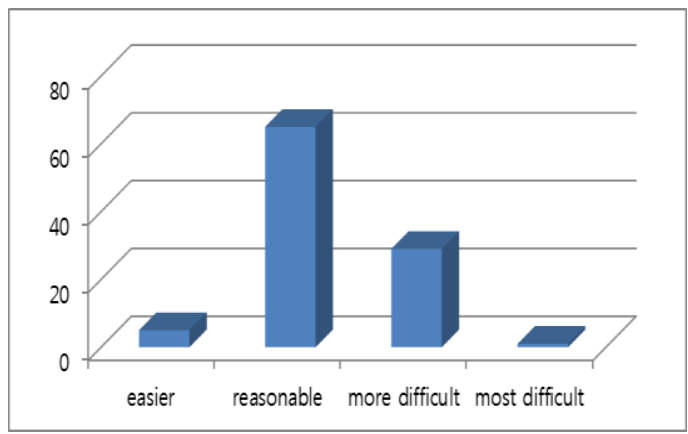

Figure 9. Survey Results for Gameplay Difficulty 


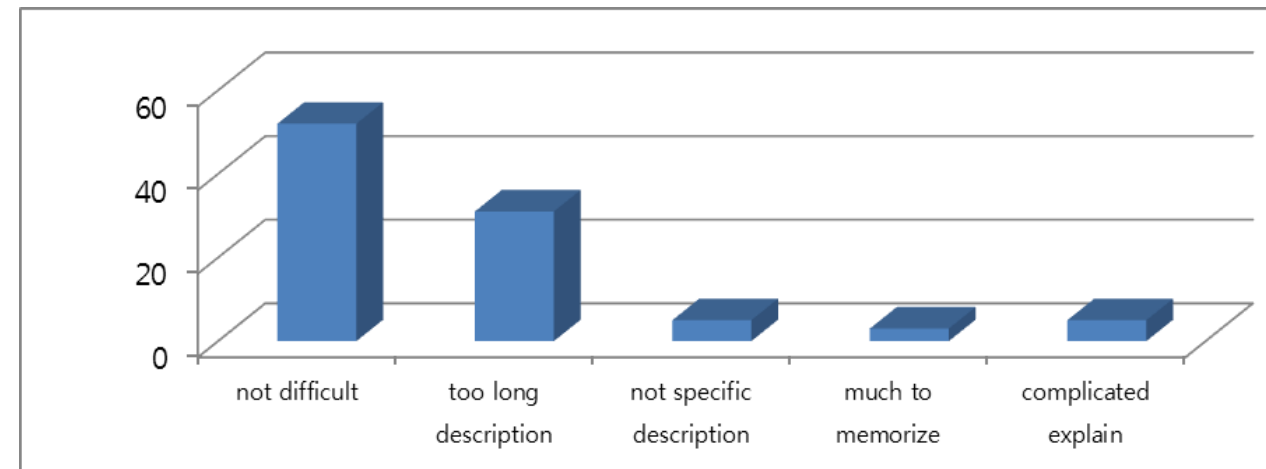

Figure 10. Survey Results for Information of Gameplay

\section{Conclusion}

This case study on an analysis of key success faetor by production process of a serious game for the elderly was performed through strict clinical triak and play tests. So I found some key success factors by production process as follows: Each stage of production has some key success factors. First, they had understood enough the state of growing elderly population in South Korea and designed gameplay well for improving cognitive function for the elderly. Second, they organized a development teanincluding some experts and made use of the feature as a RF card. Third, they validated the effectiveness of a serious game through clinical trials and play tests. Thîs seribus game suggested new possibilities in the barren market for serious games in South Korea. This paper will help for serious game design and could be the guideline for the development of serious game for elderly. But this paper has limitations as a case study, and this game is in the earlier stage of commercialization. Thus additional research for success factors of serious game since commercialization will be necessary.

\section{Acknowledgements}

This work was supported by the National Research Foundation of Korea (NRF) grant funded by the Korean Goyernment (2013- A001-0104)

\section{References}

[1] U. Ritterfeld M. Cody and P. Vorderer, "Serious Games: Mechanisms and Effects", Routledge, (2009), pp. 39

[2] H. Koon, "A Study on Analysis of a Serious Game: An Online Game "Allep", Journal of Korean Society for Computer Game, vol. 2, no. 24, (2011) June.

[3] Korea Creative Content Agency, Serious Game Status and Promotion Strategies, Research Report 13-11, p.47.

[4] Korea Creative Content Agency, Survey on Korean Serious Game Business and Case Study of Serious Games. 2014, p.15.

[5] Y. Y. Doh, “A Systematic Approach to Evaluate Player's Experience”, Serious Game Research Forum Seminar proceeding, (2013).

[6] Ministry of Health and Welfare, Statistical Year Book, (2013). vol. 59.

[7] Ministry of Health and Welfare, Korea Institute for Health and Social Affairs, (2011), Senior Survey.

[8] P. M. Kato, S. W. Cole, A. S. Bradlyn and B. H. Pollock, "A Video Game Improves Behavioral Outcomes in Adolescents and Young Adults with Cancer: A Randomized Trial", Pediatrics, (2008), p. 122.

[9] A. R. Jadad, R. A. Moore, D. Carroll, C. Jenkinson, D. J. M. Reynolds, D. J. Gavaghan and H. J. McQuay, "Assessing the quality of reports of randomized clinical trials: Is blinding necessary?", Controlled Clinical Trials, vol. 17, no. 1, (1996) February, pp. 1-12. 
[10] H. Yoon, "A Study on an Analysis of Success Factors by Production Process of a Serious Game for the Elderly: Focusing on an Arcade Game "Anti-Aging Village", Future Creation Convergence Research Society International Workshop 2014 proceedings, p.5.

\section{Author}

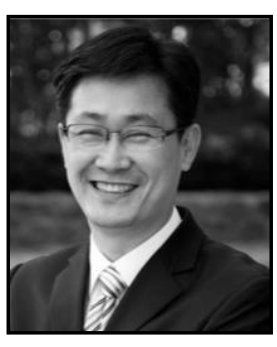

\section{Hyung Sup Yoon}

Professor of Dept. of Game Studies, Graduate School, Sangmyung University

Columnist of the Games (Weekly Magazine)

Research Professor of Institute of Contents Technology, Gachon

University

Director of Institute for Serious Games, Buruxo Co. Ltd.

Development Director of Neorigin Co. Ltá. •

Planning Director of Cyram Co. Ltd.

Director of Game Academy Team, Korea Game Industry Agency

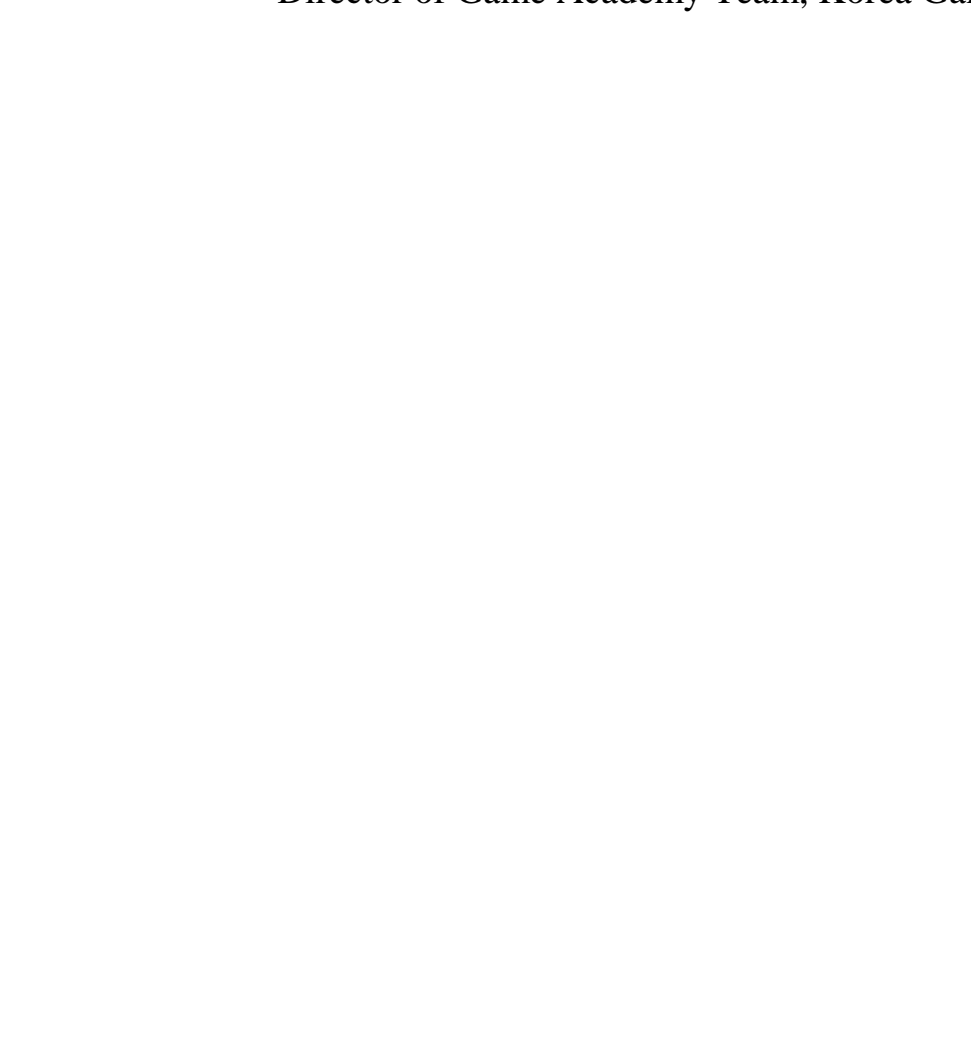

